\title{
Linfangioma quístico de origen adrenal Cystic adrenal lymphangioma
}

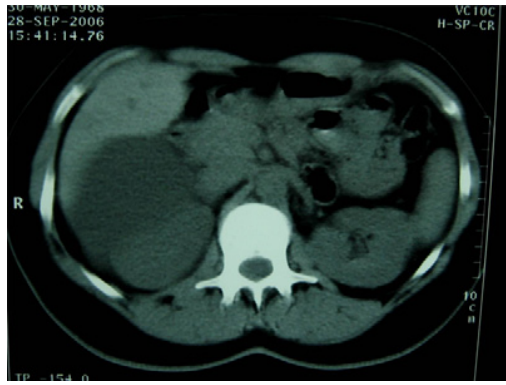

Imagen 1 - TAC: Corte transversal a nivel de los riñones, donde se observa el desplazamiento del riñón derecho por una imagen quística de contenido homogéneo.

J. Navarro Gil*, J. Subirá Ríos, J. García Magarino, D. García Calero, J.M. Sánchez Zalabardo y

J.G. Valdivia Uría

Servicio de Urología, Hospital Clínico Universitario «Lozano Blesa», Zaragoza

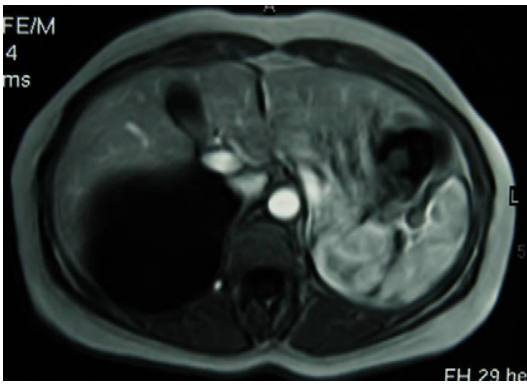

Imagen 2 - RNM: Corte transversal y longitudinal. Imagen bien delimitada de contenido líquido.

*Autor para correspondencia.

Correo electrónico: telonman@hotmail.com (J. Navarro Gil)

doi: 10.1016/j.acuro.2010.02.005

\section{Heridas por perdigones}

\section{Gun shot injury}

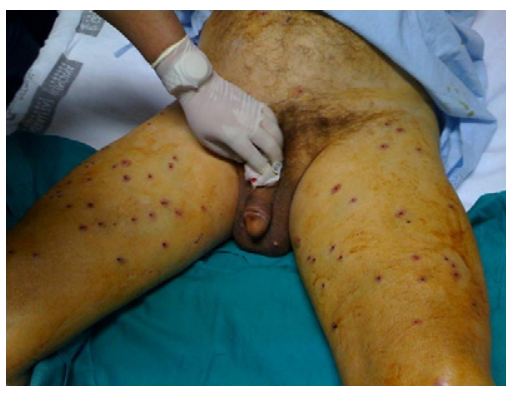

Figura 1 - Quemaduras superficiales de pequeño tamaño provocadas por perdigones en región pelviana y parte superior de los muslos.

C. Pérez Tomás*, C. Pérez Tomás, J.A. Galán LLopis, E. Herrero Polo y J.J. Lobato Encinas

Servicio de Urología, Hospital General Universitario de Alicante, Alicante, España

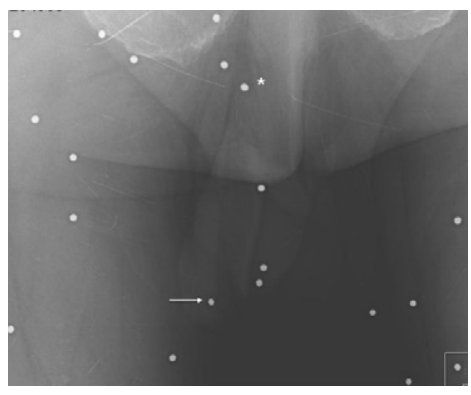

Figura 2 - Radiografía simple mostrando perdigones en la cara dorsal de la base del pene, cara anterior del escroto y glande.

\footnotetext{
*Autor para correspondencia.

Correo electrónico: Carlotilla@yahoo.com (C. Pérez Tomás)
}

doi: 10.1016/j.acuro.2010.02.006 